\title{
Gesture Identification in a Person with Crossed Aphasia: A Case Study
}

\author{
Nikitha $M^{1^{*}}$ and SP Goswami \\ ${ }^{1}$ Junior Research Fellow, Department of Speech Language Pathology, All India Institute of Speech and \\ Hearing, Mysuru, India \\ ${ }^{2}$ Professor of Speech Pathology, Department of Speech Language Pathology, All India Institute of Speech \\ and Hearing, Mysuru, India
}

*Corresponding author: Nikitha M, Junior Research Fellow, Department of Speech language pathology, All India Institute of Speech and Hearing, Mysuru, India

\begin{abstract}
Introduction: Gesture and verbal language share a longstanding association due to which they have been studied together. These studies have much of a clinical importance in aphasia research. It is widely known that left hemisphere is involved in language processing and right hemisphere in visuo-spatial skills. Gestures being a visuo-spatial phenomenon become even more interesting to be studied in a person with right hemisphere lesion.

Case description: We present case details of a 44-yearold female person with crossed aphasia (PWCA). A detailed report on verbal language and gesture identification skills is presented. Gesture identification was assessed using a Gesture Naming (GN) task for a set of 15 noun and 15 verb gesture video stimuli. The results revealed compromised gesture identification for both noun and verb gestures with varied naming errors. However, the naming errors made indicated some level of activation in terms of language processing.
\end{abstract}

Conclusion: The findings of both verbal language and gesture task have pointed compromised abilities. Both the modalities have shown problems at the level of language formulation and articulation with spared conceptualization. These findings further support the integrated system hypothesis of gesture and speech relationship.

\section{Keywords}

Gesture naming, Language, Crossed aphasia

\section{Introduction}

Gestures are the arm, hand, or bodily movements to express thoughts, needs, or personal and emotional feelings [1]. Gestures and verbal language (i.e., speech) have always been associated at different levels of language processing and they can have divergent roles in human communication. Gestures serve in planning and organizing spoken language in terms of visuo-spatial alignment of information [2,3]. On the contrary, they are directly linked to the communication partner and serve the communicative purpose $[4,5]$ by complementing (add on or redundancy) or replacing the spoken language. According to the former, gesture and speech are integrated and the interaction happens at the early stages of comprehension [6-8] which aids in prelexical processing [9-11]. However, the latter believes, gestures and speech are in independent systems and help in post-lexical processing [12].

Owing to the close association of gesture and verbal language, gesture studies in aphasia have been carried out in terms of gesture comprehension $[13,14]$ and production abilities $[15,16]$ mimicking the verbal language domains. These studies have yielded two opposing notions of gesture and speech relationship: (a) Parallel breakdown phenomenon, wherein language impairments affects both gesture and speech modality to the same extent $[17,18]$ and (b) Trade-off hypothesis, wherein gesture may alternate or augment for the spoken language impairment $[19,20]$. We speculate that the complex nature of interaction between gestures and speech at various levels of language processing (comprehension and production) could have resulted in varied findings in aphasia research.

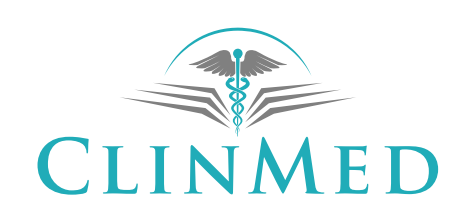

INTERNATIONAL LIBRARY

Citation: Nikitha M, Goswami SP (2022) Gesture Identification in a Person with Crossed Aphasia: A Case Study. Int Arch Commun Disord 4:019. doi.org/10.23937/2643-4148/1710019

Accepted: February 22, 2022: Published: February 24, 2022

Copyright: (c) 2022 Nikitha M, et al. This is an open-access article distributed under the terms of the Creative Commons Attribution License, which permits unrestricted use, distribution, and reproduction in any medium, provided the original author and source are credited. 


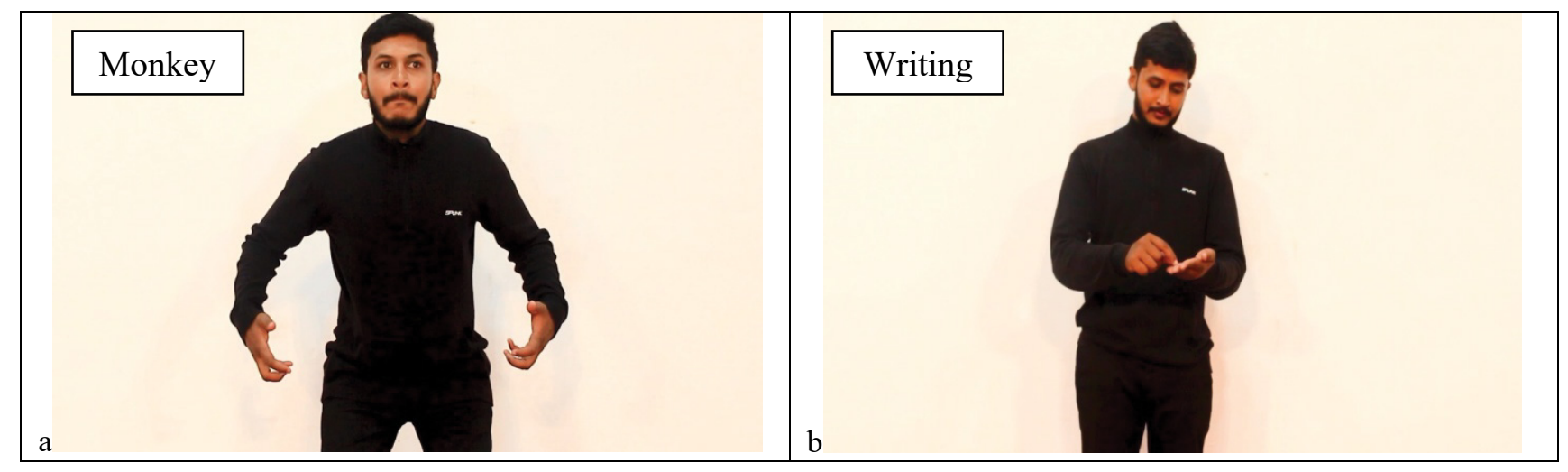

Figure 1: Examples of stimuli under the gesture naming task (a) Noun gesture stimulus depicting the animal 'monkey'; b) Verb gesture stimulus depicting the action of 'writing'.

In general, left hemisphere lesion causes language deficits and right hemisphere lesion result in constructional and visuo-spatial impairments [21]. Conversely, language deficits due to right hemisphere lesions are also observed. Bramwell [22] introduced the term 'Crossed Aphasia' (CA), a condition caused from a brain lesion on the same side to their dominant hand. Initially, it was believed that long-standing conditions of such aphasias are commonly found in left-handed individuals; however, studies on righthanded individuals have shown the vice-versa $[23,24]$ in the later years. This has resulted in the term "crossed aphasia in dextrals" (CAD) and is synonymously used with CA [25]. The diagnosis of CA in right-handed persons with aphasia must satisfy the four diagnostic criteria framed by Brown and Wilson [26]: a) Aphasia on a formal language test, b) Confined lesion in the right hemisphere, c) No past history of brain damage, and d) No family history of left-handedness. CA has few possible explanations which include: a) An unknown lesion in the left hemisphere which started showing obvious symptoms by a newly formed right hemisphere lesion, b) Right hand controlled by the same side of the brain, c) Language functions represented bilaterally, d) Reduced lateralization of language function during the developmental years [27]. Thereby, similar, and distinct language features could be expected in CA as compared to conventional aphasia symptoms.

Persons with crossed aphasia (PWCA) present with a wide range of language disturbances along with deficits in gestures and visuo-spatial abilities [25]. Further, lesions in sub-cortical structures of either of the hemisphere also cause aphasic symptoms in PWCA $[28,29]$. Dysprosody, visual neglect, apraxia, acalculia and disturbance of orientation and memory have been some of the reported symptoms of CA of sub-cortical origin [30]. Gestures being visuo-spatial in nature and considered as 'visible action' of verbal language [31]; it becomes interesting to know gesture skills in PWCA with right hemisphere sub-cortical lesion. We present one such case study on a PWCA whose gesture skills were assessed in terms of gesture identification. This could throw light on gesture and verbal language relationship and its role in language processing in persons with atypical brain damage.

We have used Gesture Naming (GN) task to understand the gesture identification in our patient with CA. The task, expected verbal naming of the gesture video (noun or verb) presented. A set of 15 noun and 15 verb gesture videos were randomly selected from a gesture corpus study [32]. The stimuli were presented one at a time on a laptop screen as depicted in Figure 1 for a maximum of two times. The patient was instructed as follows "You will be shown a gesture video (noun or verb), watch the video completely and name it". The responses were audio- video recorded to analyze for accuracy and verbal naming errors. A scoring of 1 or 0 was given for correct and incorrect responses respectively, for a total score of 30 . Correct responses included naming of noun/verb gesture with self repairs, dialect forms and phonological errors in which the target was clearly recognizable. Incorrect responses consisted of any semantic paraphasias, circumlocutions, and irrelevant errors along with no responses. The patient details along with verbal language abilities and gesture naming abilities is presented below.

\section{Case Description}

\section{Participant details}

Ms. VL, 44-year-old female reported weakness of the left side of the body along with difficulty in expressing and difficulty in writing. These symptoms had manifested post-stroke 2 years ago. Though early rehabilitation services were availed at 3 months poststroke for a span of 1 year, the above-mentioned symptoms have persisted; but to a lesser extent. The patient is a Bachelor's in Science (B Sc.) and Bachelor's in Education (B Ed.) graduate who worked as a high school teacher. The patient is a native Kannada speaker and a right-handed individual pre-morbid and has continued to be the same post-morbid. 


\section{Medical history}

A 44-year-old female has been on medications (Tab. Oxetal and Tab. Clobazam) for seizure disorder since six years with no known family history. Her seizures have been well controlled with no episodes since 4 years. In 2017, she was admitted to a neurology care with repeated complaints of headache and was diagnosed as having right ophthalmic segment internal carotid artery (ICA) aneurysm. She underwent flow diverter placement procedure for the diagnosed cerebral aneurysm immediately. However, two days post surgery she developed sudden weakness of left upper and lower limbs with drowsiness. Computerized tomography (CT) scan of brain showed intra-parenchymal hemorrhage with hematoma in the right external capsule region. Magnetic resonance imaging (MRI) of brain showed hematoma in right external capsule, putamen, carona radiata and part of semi-ovale. A few sessions of physiotherapy were given for the weakness shown, following which the patient was discharged. Three months post discharge, the patient started with continuous speech language therapy (SLT) along with physiotherapy (PT) for one year. Further, she continued home training and intermittent rehabilitation services (SLT and PT) for another year. In 2019, CT angiography of brain was done, as a follow up. This revealed chronic infarct with gliosis in right carona radiata and right basal ganglia along with ex-vacuo dilation of right lateral ventricle, stenting of cavernous and supraclinoid portions of right ICA was also noted (post-op status).

\section{Language profile}

Informal evaluation revealed that Ms. VL communicates verbally using adequate sentence. However, word finding difficulty and phonemic paraphasias are present. She comprehends most of the instructions and daily routine activities but has difficulty in complex cognitive-linguistic activities like

Table 1: Description of WAB score of Ms. VL.

\begin{tabular}{|c|c|c|c|}
\hline WAB domains & Max score & Patient score & Total \\
\hline \multicolumn{4}{|l|}{ Spontaneous speech } \\
\hline Information content & 10 & 9 & 18 \\
\hline Fluency & 10 & 9 & \\
\hline \multicolumn{4}{|l|}{ Auditory Verbal Comprehension } \\
\hline Yes/no question & 60 & 60 & \\
\hline Auditory word recognition & 60 & 59 & 199 \\
\hline Sequential commands & 80 & 80 & \\
\hline \multicolumn{4}{|l|}{ Repetition } \\
\hline & 100 & 85 & 85 \\
\hline \multicolumn{4}{|l|}{ Naming } \\
\hline Objective naming & 60 & 60 & \\
\hline Word fluency & 20 & 8 & 84 \\
\hline Sentence completion & 10 & 6 & \\
\hline Responsive speech & 10 & 10 & \\
\hline \multicolumn{4}{|l|}{ Reading and Writing } \\
\hline Reading & 100 & 100 & \\
\hline Writing & 100 & 84 & 184 \\
\hline \multicolumn{4}{|l|}{ Praxis } \\
\hline & 60 & 60 & 60 \\
\hline \multicolumn{4}{|l|}{ Construction } \\
\hline Drawing & 30 & 30 & \\
\hline Block design & 9 & 7 & 88 \\
\hline Calculation & 24 & 24 & \\
\hline Raven's score & 37 & 27 & \\
\hline
\end{tabular}

WAB: Western Aphasia Battery 
auditory memory, visual sequencing, set maintenance, abstract reasoning and problem solving. Oral peripheral mechanism examination (OPME) showed adequate structures with functions being very slightly affected. A slight asymmetry and reduced range of movements of lips and tongue was noticed on keen observation. Formal language evaluation using Western Aphasia Battery- Kannada (WAB-K) [33] revealed that Ms. VL had mild aphasia of anomic type with an aphasia quotient (AQ) of 89.7, cortical quotient (CQ) of 92 and Language quotient (LQ) of 81.6. All the four major WAB domains were performed well with few difficulties (Spontaneous speech $=18 / 20$, Auditory verbal comprehension = 199 $/ 200$, Repetition $=85 / 100$, Naming $=84 / 100$, Reading and writing $=184 / 200$, Praxis $=60 / 60$, Construction = 88/100; see Table 1). In the spontaneous speech domain of WAB, she was able to respond in complete sentences for all the questions asked and described the picture by naming the items of it. However, hesitations, paraphasias, word finding difficulty with some articulatory errors were seen. Auditory verbal comprehension domain of WAB seemed to have almost no difficulty as the patient followed the entire yes/no questions, recognized the words and performed well on the sequential commands. Repetition of longer sentences was affected with phonemic paraphasias and poor sentence order; could be due to attentional and working memory deficits. In the naming domain, object naming, sentence completion and responsive speech were spared compared to her word fluency. Ms. VL did not show any reading difficulties however, her written output was slightly affected with poor sentence construction and organization along with spelling errors. She did not show any praxis errors or difficulties in construction (drawing) or calculation (addition, subtraction, multiplication and division) skills. But, her visuo-spatial skills as seen on block design task was slightly affected (block design task score $=7 / 9$ ) along with poor scores on Raven's coloured progressive matrices (RCPM score $=27 / 37$ ); indication of affected cognition and abstract reasoning. Additionally, Ms. VL was administered a visual screening test taken from "Battery for Cognitive Communication- Kannada" (BCC-K) [34]; she performed well and did not show any visual deficits. Further, Mini Mini-Mental State Examination (MMSE) [35] was administered to rule out any cognitive or degenerative conditions, which again did not show any deficits (MMSE score $=28 / 30$ ).

\section{Performance on GN task}

Ms. VL procured a score of 19/30 (9/15 for noun and $10 / 15$ for verb gestures), revealing a difficulty in naming the target noun or verb gesture video. She showed a variety of errors while naming the target gestures such as: a) Explanatory error (ER) or circumlocutions: A naming error wherein the description of the gesture is given as response, b) Semantic related error (SR): A naming error wherein a semantically related word, super-ordinate or sub-ordinate word is given as response c) Unrelated error (UR): A naming error which is not related to the target in any means and d) No response (NR): Failure to provide any response to the target gesture even with additional trials (see Appendix A for description of errors).

\section{Discussion}

Firstly, Ms. VL satisfied all the four criteria given by Brown and Wilson [26] for the diagnostic label of CA. However, involvement of left hemisphere cannot be ruled out due to the previously existing seizure disorder; though, the presence of the lesion in the right hemisphere was the major cause for her aphasia symptoms. Probably, the unknown involvement of the left hemisphere could have been the reason for the CA [27] in our case; as a speculation. Thorough search of previously available language reports and case history taking with the informant (Ms. VLs' spouse) revealed that the initially symptoms have almost matched aphasia of wernicke's type (fluent type) except for the spared comprehension. Her initial symptoms have revealed fluent jargon with paraphasias and intact comprehension on simple tasks compared to complex ones. Though the lesion has majorly involved the sub-cortical structures of the right hemisphere; typical symptoms of sub-cortical CA such as dysprosody, visual neglect, apraxia, acalculia and disturbance of orientation and memory [30] was not observed. However, the language symptoms coincide with the PWCA reported by Habib, Joantte, Ali-Cherif and Poncet [36], whose language features could neither be attributed to wernicke's or conduction type of fluent aphasias and who also had lesion in the parts of right basal ganglia (putamen and caudate nucleus).

The clinical symptoms of Ms. VL have matched the fluent variant of aphasia and more specifically anomic type on WAB. This is unlike the past reports on CA which has shown that the most common symptoms of CA to have matched the non-fluent type over the fluent type of aphasias [29,37]. However, these reports of Ms. VL are based on the language profile drawn 2 years post onset. And also, the very initial symptoms of Ms. VL during the hospital stay or during her initial phase of acute stage could have been non-fluent type, which cannot be ruled out. But these symptoms in Ms. VL have improved over time. She currently presents with only word finding difficulty (which is accompanied by hesitations, paraphasias, and circumlocutions), organizational difficulty in discourse and writing, poor sentence construction (for speaking and writing) and difficulty maintaining sentence order on repetition along with left upper limb hemiparesis. These language behaviors were grouped under the anomic type of aphasia as on WAB.

The performance on the GN task has shown difficulty in correctly identifying and naming the target gesture. This was evident from the accuracy score and from the 
varied naming errors made. Ms. VL has named $63.33 \%$ of the gesture stimuli correctly with the following the naming errors: ER (4), SR (4), UR (1) and NR (2). The majority of the errors comprised of ER and SR which indicates a presence of some language activation as these errors were somehow related to the target. ERs' were majorly seen for the verb gestures while the SRs' were seen for noun gestures. In general, the verb gestures describe series of action of the target verb while the noun gestures depict the physical and functional attribute of the target noun. One can speculate that nature of these gestures itself could have resulted in these specific errors. We infer that there was no difficulty in perceiving the gesture similar to comprehending verbal stimuli; however, execution or naming the same was difficult. Taking insights from the Levelt's model [38]; there exist three stages in language production: (1) Conceptualization, (2) Formulation, and (3) Articulation. The combined results of both verbal language and gesture naming abilities of Ms. VL has revealed a slightly compromised formulation and articulation phase with spared conceptualization phase. If we could compare the performance on $\mathrm{GN}$ task with the four verbal language domains of WAB; one can draw parallel lines with gesture and verbal language. An integration of gesture and speech systems at the same level and at the early pre-lexical processing is speculated. Thereby, one can deduce a parallel breakdown of gesture and verbal language skills in our patient which supports the integrated system hypothesis of gesture and speech relationship.

\section{Limitations}

As in any other research, this case report is also not free from shortcomings. To the best knowledge of the investigator, we admit two of the major limitations: (1) Post onset duration: this is one of the essential variables to be considered while making a language evaluation. The most ideal time window to make anatomo-behavioral correlations post morbid ranges between three weeks to three months [25]. The post onset duration in this patient has been almost 2 years; this would limit the symptom and lesion correlations of the study due to functional compensation. (2) Previous brain damage: an early developmental brain damage or seizures could influence the functional organization of the brain and has to be kept as an exclusion criterion in the diagnosis of CA [25]. However, our patient though had a past history of seizure disorder for 5 years was still considered for the diagnosis of CA; as the onset of seizures had been in the adulthood and the language symptoms had clear onset post morbid (since 2 years). Further, the seizure disorder in Ms. VL was well controlled.

\section{Clinical implications}

This case report adds on to the evidence of integrated system hypothesis of gesture and speech.
There are varied reports of case documents in aphasia research, which have reported good gesture abilities $[39,40]$; while, poor gesture abilities have also been noted in them $[41,42]$. However, language treatment when combined with gestures promotes noun and verb naming [43]. Therefore, we recommend use of multimodal approach in assessment and therapeutics; and not to restrict to only verbal mode, even in cases of CA. Use of various modalities could mutually benefit and aid the other in communication processes.

\section{Acknowledgements}

We would like to thank the Director, All India Institute of Speech and Hearing, Mysore (affiliated to University of Mysore) for permitting us to carry out the research. A special thanks to our patient and her family for their cooperation.

\section{References}

1. Knapp ML, Hall JA (1997) Nonverbal communication in human interaction. Fort Worth, TX: Harcourt Brace College Publishers.

2. Hostetter AB, Alibali MW, Kita S (2007) I see it in my hands' eye: Representational gestures reflect conceptual demands. Language and Cognitive Processes 22: 313-336.

3. Kita S (2000) How representational gestures help speaking. Language and gesture 1: 162-185.

4. Goldin-Meadow S (2003) Hearing gesture: How our hands help us think. Harvard University Press.

5. McNeill D (1985) So you think gestures are nonverbal? Psychological review 92: 350.

6. Cassell J, McNeill D, McCullough KE (1999) Speech-gesture mismatches: Evidence for one underlying representation of linguistic and nonlinguistic information. Pragmatics \& Cognition 7: 1-34.

7. Kelly SD, Barr DJ, Church RB, Lynch K (1999) Offering a hand to pragmatic understanding: The role of speech and gesture in comprehension and memory. Journal of memory and Language 40: 577-592.

8. McNeill D (1992) Hand and mind: What gestures reveal about thought. University of Chicago Press.

9. De Ruiter JP (2000) The production of gesture and speech. Language and Gesture 3: 284-311.

10. Kita S, Özyürek A (2003) What does cross-linguistic variation in semantic coordination of speech and gesture reveal?: Evidence for an interface representation of spatial thinking and speaking. Journal of Memory and Language 48: 16-32.

11. McNeill D (2000) Language and gesture. Cambridge: Cambridge University Press.

12. Rauscher FH, Krauss RM, Chen Y (1996) Gesture, speech, and lexical access: The role of lexical movements in speech production. Psychological Science 7: 226-231.

13. Schmid G, Ziegler W (2006) Audio-visual matching of speech and non-speech oral gestures in patients with aphasia and apraxia of speech. Neuropsychologia 44: 546555.

14. Cocks N, Byrne S, Pritchard M, Morgan G, Dipper L (2018) Integration of speech and gesture in aphasia. International 
Journal of Language \& Communication Disorders 53: 584591.

15. Pritchard M, Dipper L, Morgan G, Cocks N (2015) Language and iconic gesture use in procedural discourse by speakers with aphasia. Aphasiology 29: 826-844.

16. Sekine K, Rose ML, Foster AM, Attard MC, Lanyon LE (2013) Gesture production patterns in aphasic discourse: Indepth description and preliminary predictions. Aphasiology 27: 1031-1049.

17. Cicone M, Wapner W, Foldi N, Zurif E, Gardner H (1979) The relation between gesture and language in aphasic communication. Brain and Language 8: 324-349.

18. Glosser G, Wiener M, Kaplan E (1986) Communicative gestures in aphasia. Brain and Language 27: 345-359.

19. De Ruiter JP (2006) Can gesticulation help aphasic people speak, or rather, communicate?. Advances in Speech Language Pathology 8: 124-127.

20. Herrmann M, Reichle T, Lucius-Hoene G, Wallesch CW, Johannsen-Horbach $\mathrm{H}$ (1988) Nonverbal communication as a compensative strategy for severely nonfluent aphasics? - A quantitative approach. Brain and Language 33: 41-54.

21. Knecht S, Deppe M, Dräger B, Bobe L, Lohmann $H$, et al. (2000) Language lateralization in healthy right-handers. Brain 123: 74-81.

22. Bramwell B (1899) On" crossed" aphasia and the factors which go to determine whether the" leading" or" driving" speech-centres shall be located in the left or in the right hemisphere of the brain: With notes of a case of" crossed" aphasia (aphasia with right-sided hemiplegia) in a lefthanded man. The Lancet 153: 1473-1479.

23. Humphrey ME, Zangwill OL (1952) Dysphasia in lefthanded patients with unilateral brain lesions. J Neurol Neurosurg Psychiatry 15: 184.

24. Goodglass H, Quadfasel FA (1954) Language laterality in left-handed aphasics. Brain 77: 521-548.

25. Mariën P, Paghera B, De Deyn PP, Vignolo LA (2004) Adult crossed aphasia in dextrals revisited. Cortex 40: 41-74.

26. Brown JW, Wilson FR (1973) Crossed aphasia in a dextral: A case report. Neurology 23: 907-911.

27. Bakar M, Kirshner HS, Wertz RT (1996) Crossed aphasia: functional brain imaging with PET or SPECT. Archives of Neurology 53: 1026-1032.

28. Holmes JE, Sadoff RL (1966) Aphasia due to a right hemisphere tumor in a right-handed man. Neurology 16 : 392.
29. Kim WJ, Yang EJ, Paik NJ (2013) Neural substrate responsible for crossed aphasia. Journal of Korean Medical Science 28: 1529-1533.

30. De Witte L, Verhoeven J, Engelborghs S, De Deyn PP, Mariën P (2008) Crossed aphasia and visuo-spatial neglect following a right thalamic stroke: a case study and review of the literature. Behavioural Neurology 19: 177-194.

31. Kendon A (2004) Gesture: Visible action as utterance. Cambridge University Press.

32. Nikitha M, Goswami SP (2021) (in press) An Indian Corpus of Gestures for Nouns and Verbs: A Preliminary Study. Research and Reviews: Journal of Neuroscience.

33. Chengappa SK, Kumar R (2008) Normative \& Clinical Data on the Kannada Version of Western Aphasia Battery (WAB-K). Language in India 8.

34. Goswami SP, Varun Uthappa AG, Murali Krishna, Julie Hengst A, Suma DR, et al. (2019) Development of Battery for Cognitive Communication- Kannada" (BCC-K). Project, All India Institute of Speech and Hearing.

35. Rovner BW, Folstein MF (1987) Mini-mental state exam in clinical practice. Hospital Practice (Off Ed) 22: 99-103.

36. Habib M, Joanette Y, Ali-Cherif A, Poncet M (1983) Crossed aphasia in dextrals: a case report with special reference to site of lesion. Neuropsychologia 21: 413-418.

37. Carr MS, Jacobson T, Boller F (1981) Crossed aphasia: analysis of four cases. Brain and Language 14: 190-202.

38. Levelt WJ, JM W (1989) Speaking: From intention to articulation. A bradford book, MIT Press.

39. Kemmerer D, Chandrasekaran B, Tranel D (2007) A case of impaired verbalization but preserved gesticulation of motion events. Cognitive Neuropsychology 24: 70-114.

40. Wilkinson R, Beeke S, Maxim J (2010) Formulating actions and events with limited linguistic resources: Enactment and iconicity in agrammatic aphasic talk. Research on Language and Social Interaction 43: 57-84.

41. Duffy RJ, Duffy JR (1981) Three studies of deficits in pantomimic expression and pantomimic recognition in aphasia. Journal of Speech, Language, and Hearing Research 24: 70-84.

42. Duffy RJ, Watt JH, Duffy JR (1994) Testing causal theories of pantomimic deficits in aphasia using path analysis. Aphasiology 8: 361-379.

43. Raymer AM, McHose B, Smith KG, Iman L, Ambrose A, et al. (2012) Contrasting effects of errorless naming treatment and gestural facilitation for word retrieval in aphasia. Neuropsychological Rehabilitation 22: 235-266. 
Appendix A: Description of errors made by Ms. VL on GN task.

\begin{tabular}{|c|c|c|c|c|}
\hline Target & Stimuli type & Response & Error type & Remarks \\
\hline Screwdriver & Noun & Screw & SR & $\begin{array}{l}\text { It is a within the category naming and a visuo-semantic } \\
\text { error which is considered as SR. The gestures to them } \\
\text { are also visually similar }\end{array}$ \\
\hline Cricket Bat & Noun & Hockey & SR & $\begin{array}{l}\text { It is again a visuo-semantic and within category naming } \\
\text { marked as SR }\end{array}$ \\
\hline Saw & Noun & Hammer & SR & $\begin{array}{l}\text { Within the category naming which shares a semantic } \\
\text { association }\end{array}$ \\
\hline Weight lifting & Verb & Exercise & SR & $\begin{array}{l}\text { Broad category naming instead of specific item naming } \\
\text { was noted which is considered as SR }\end{array}$ \\
\hline Lemon & Noun & Juice making & ER & $\begin{array}{l}\text { Parts of the action is being described instead of target } \\
\text { item naming which is considered as ER }\end{array}$ \\
\hline Stitching & Verb & $\begin{array}{l}\text { Using needle } \\
\text { and thread on } \\
\text { the cloth }\end{array}$ & ER & $\begin{array}{l}\text { Explaining the process of the action instead of naming the } \\
\text { verb which is considered as circumlocution or ER }\end{array}$ \\
\hline Cooking & Verb & $\begin{array}{l}\text { Keeping a } \\
\text { vessel on the } \\
\text { stove and } \\
\text { stirring }\end{array}$ & ER & $\begin{array}{l}\text { Failure to name the target verb and describing the parts } \\
\text { of the gesture, hence, considered as an ER }\end{array}$ \\
\hline Kneeling & Verb & Sit and stand & ER & $\begin{array}{l}\text { Description of the gesture instead of naming the specific } \\
\text { verb }\end{array}$ \\
\hline Mixer & Noun & Swing & UR & $\begin{array}{l}\text { This response is not related to the target in any means } \\
\text { hence considered as an UR }\end{array}$ \\
\hline Clock & Noun & $\begin{array}{l}\text { Imitated the } \\
\text { gesture }\end{array}$ & NR & No verbal naming of the target \\
\hline Pushing & Verb & $\begin{array}{l}\text { Imitated the } \\
\text { gesture }\end{array}$ & NR & No verbal naming of the target \\
\hline
\end{tabular}

SR: Semantically Related Error; ER: Explanatory Error; UR: Unrelated Error; NR: No Response 